\title{
Are Tuberculosis Patients Managed According to the National Guidelines in Lagos State Nigeria?
}

\author{
Olusola Adedeji Adejumo1 ${ }^{*}$, Olusoji James Daniel2, Mustapha Gidado3, \\ Andrew Folarin Otesanya4, Esther Ngozi Adejumo5, Ebunoluwa 0. Jaiyesimi², \\ Oluwatoyin Esther Idowu', Olumuyiwa 0. Odusanya ${ }^{6}$ \\ ${ }^{1}$ Department of Community Health and Primary Health Care, Lagos State University Teaching Hospital, Ikeja \\ Lagos, Nigeria \\ ${ }^{2}$ Department of Community Medicine and Primary Care, Olabisi Onabanjo University Teaching Hospital, \\ Sagamu, Nigeria \\ ${ }^{3}$ KNCV Tuberculosis Foundation/TB CARE I Project, Abuja, Nigeria \\ ${ }^{4}$ Medical Services Department Central Bank of Nigeria, Lagos, Nigeria \\ ${ }^{5}$ Department of Medical Laboratory Science, Babcock University, Ilisan-Remo, Nigeria \\ ${ }^{6}$ Department of Community Health and Primary Health Care, College of Medicine Lagos, Lagos State University, \\ Lagos, Nigeria \\ Email: "drolus_adejumo@yahoo.com,oluadejumo75@gmail.com
}

Received 14 December 2015; accepted 17 January 2016; published 20 January 2016

Copyright (C) 2016 by authors and Scientific Research Publishing Inc.

This work is licensed under the Creative Commons Attribution International License (CC BY).

http://creativecommons.org/licenses/by/4.0/

(c) (i) Open Access

\section{Abstract}

Setting: Private and public tuberculosis (TB) treatment centers in Lagos State, Nigeria. Objective: To compare adherence of private and public providers of directly observed treatment short course (DOTS) in the Lagos State TB control program, Nigeria (LSTBLCP) with the national TB guidelines. Design: A retrospective review of treatment cards of TB patients managed within the first and second quarter of 2012 in 34 DOTS facilities $\{23$ public, 7 private for profit (PFP), and 4 private not for profit (PNFP)\} involved in the private public mix of the LSTBLCP. Results: Of the 1896 treatment cards reviewed, $1524(80.4 \%), 132(7.0 \%)$ and $240(12.6 \%)$ were from public, PFP and PNFP DOTS facilities, respectively. About $19 \%, 25 \%$ and none of the patients managed at the public, PNFP, and PFP DOTS facilities were treated in full adherence with the national guidelines respectively. A significantly higher proportion of adults and sputum smear positive TB patients were treated in full adherence with the national guidelines $(p<0.05)$. Treatment success was associated with full adherence with the national guidelines. Conclusion: There is a need to reorient health care providers in public and private health facilities in Lagos State Nigeria to ensure full adherence with the national TB guidelines.

\footnotetext{
${ }^{*}$ Corresponding author.
} 


\section{Keywords}

\section{Adherence, National Guidelines, Health Workers, DOTS Facilities}

\section{Introduction}

Tuberculosis (TB) is still a serious public health issue in Nigeria accounting for 46,000 deaths (27 per 100,000 populations) per year [1]. The 2012 national TB prevalence survey showed that the prevalence of smear positive TB in Nigeria (318 per 100,000) was about twice as much as the previous World Health Organization (WHO) estimate, which was based on routine surveillance data [2]. This recent figure placed Nigeria $4^{\text {th }}$ among the 22 high burden TB countries [3]. Another WHO report showed that 2.9\% $(2.1 \%-4.0 \%)$ of TB cases in Nigeria present with multi drug resistant TB [4]. Despite the efforts of the National TB and Leprosy Control Program (NTBLCP) since the commencement of directly observed treatment short course (DOTS) for management of TB in 1993, inadequate skills and poor knowledge of health care providers and programme officers at the DOTS centers were some of the barriers of TB control in Nigeria [1] [5].

Adherence to the national TB guidelines is therefore necessary in ensuring that TB patients get quality service irrespective of the service point. Thus, successful treatment could be achieved if the healthcare workers (both public and private medical practitioners) follow the national guidelines for the treatment of TB.

This present study compared adherence of private and public DOTS providers with the national guidelines and the factors associated with adherence with the national guidelines in the Lagos State TB control program, Nigeria.

\section{Methods}

\subsection{Study Setting}

Lagos state is one of the 36 states in Nigeria and the population is estimated to be 21 million.

Health care services in Lagos State are provided by both the public and private sector. In the public sector, services are organized at primary, secondary and tertiary care. There are 27 secondary, 215 primary and 1984 registered health care facilities (1925 private for profit and 59 private not for profit) in the state.

The Lagos State TB and leprosy control programme (LSTBLCP) commenced operation in 2003 in collaboration with some international organizations. In 2008, private sector participation in DOTS management of TB was introduced. To be eligible, private providers were expected to offer TB services free of cost to patients and undergo training on DOTS management of TB based on the national guidelines [6].

Based on capacity and interest, private health provider (PHP) were engaged either to refer presumptive TB patients (scheme one), provide DOTS management only (scheme two), serve as microscopy center only or serve both as treatment and microscopy center (scheme three). After training and completion of the necessary formalities, PHP were provided with recording and reporting materials, drugs and other consumables to commence TB services. The patient's treatment card was one of the recording materials provided to the PHP; it contained patients' relevant information and also served as a tool to monitor patient's treatment. Sputum microscopy results, weight measurements and drug intake were recorded on the treatment card.

TB activities in Lagos State were coordinated by the state TB control officer. At the local government level, the state TB control officer was assisted by local government TB supervisors. There are 20 TB supervisors in Lagos State, one in each LGA. They assist the state TB control officer to plan, organize and conduct training programmes, keep an up-to-date and accurate record of activities of TB control activities in the LGA. The supervisors were assisted by TB focal persons in each DOTS facility. Records of patients registered in each DOTS facility were sent to the LGA supervisors monthly and they in turn forward the records of TB patients managed in the LGA to the state control officer quarterly.

The DOTS facilities at the primary health centers (PHCs) were coordinated by Community Health Officers and nurses whereas the medical officer coordinates DOTS facilities at the secondary, tertiary, private and the military health facilities. Any health care worker could initiate treatment for smear positive TB patients; how- 
ever children and presumptive TB clients with smear negative results were referred to health facilities manned by doctors for diagnosis.

Management of TB at PHP facilities is free; however they were allowed to charge for consultation and service charge for sputum AFB microscopy because reagents and consumables for sputum AFB were freely supplied by the LSTBLCP. The PHP could also charge for investigations such as chest X-ray, erythrocyte sedimentation rate (ESR), etc. required to diagnose smear negative patients. The duration of treatment was eight months. The treatment regimen consisted of two months intensive phase of Rifampicin, Isoniazid, Pyrazinamide and Ethambutol as fixed dose combination and six months continuation phase of Rifampicin and Isonizid as fixed dose combination. Drugs were prescribed based on patient's weight and recorded on the treatment card.

According to the national guidelines, each presumptive TB patient were offered HIV testing. The HIV rapid test kit used in accordance with the national HCT policy was Determine (determine HIV-1/2 Alere Determine ${ }^{\mathrm{TM}}$, Japan 2012) and Uni-Gold ${ }^{\mathrm{TM}}$ (Trinity Biotech PLC, Wicklow, Ireland 2013) in parallel algorithm. A concordance result was regarded as positive. In the event of discordant result, STAT-PAK ${ }^{\circledR}$ was used as tie breaker. TB/HIV co-infected patients were offered CPT along with anti-TB drugs and commenced on ART within 8 weeks of anti-TB medications.

At the end of 2011, the LSTBLCP had 130 TB treatment facilities offering DOTS services. Of these, 99 were public and 31 private health care facilities (20 Private for Profit (PFP) and 11 Private not for Profit (PNFP) or missionary hospitals).

\subsection{Study Design}

A retrospective review of patients' treatment cards managed for pulmonary TB during the first and second quarter of 2012 was conducted.

A sampling frame of 130 DOTS facilities provided by the Lagos state programme officer (99 public and 31 private DOTS facilities) was used to select, 34 DOTS facilities (23 public, 7 PFP and 4 PNFP DOTS facilities) that served as both microscopy and treatment centers and were involved in DOTS programme for at least 2 years prior to the study. All treatment cards of patients managed for pulmonary TB during the first and second quarter of 2012 in the selected DOTS facilities were assessed for adherence with the national guidelines [6]. Treatment cards with wrong or missing data were not included for analysis.

\subsection{Evaluation of Compliance of Health Workers with the NTP Guidelines}

Adherence of public and private DOTS providers to the national guidelines was based on the following [6].

- Performance of smear microscopy before DOTS treatment.

- HIV test done for patients.

- Specification of patients treatment category.

- Weight measurement of patient before commencement of treatment.

- Weight measurement at least 3 times $\left(2^{\text {nd }}, 5^{\text {th }}\right.$ and $7^{\text {th }}$ month of treatment $)$.

- Three follow up sputum results at $2^{\text {nd }}, 5^{\text {th }}$ and $7^{\text {th }}$ month of treatment.

- Correct recording of sputum results.

- Correct charting of drugs.

- Correct dosages in line with the weight of the patient.

- Correct filling of treatment cards.

- Specification of the treatment outcomes.

In this study, performance of the entire task stated above was regarded as full adherence to national guidelines while incomplete performance was regarded as partial adherence.

\subsection{Definition of Treatment Outcomes}

- Treatment success was defined as the sum of the cases that were cured and that completed treatment [6].

\subsection{Data Analysis}

Data was analysed using the Statistical Package for Social Sciences (SPSS) version 19. Mean and standard deviation were calculated for numerical data while percentages were calculated for both numerical and categorical 
data. Chi square and Fishers' exact test was used to compare categorical data as appropriate. The confidence interval was set at $95 \%$ for all statistical tests. Microsoft excel was used to draw charts.

\subsection{Ethical Approval}

As data for this study were retrieved from secondary data routinely collected by the LSTBLCP, no ethical clearance was required.

\section{Results}

Treatment cards of 1896 TB patients were reviewed out of which 1524 (80.4\%), 132 (7.0\%) and 240 (12.6\%) were from the public, PFP, and PNFP DOTS facilities respectively (Figure 1). The mean age of TB patients treated at the public and private DOTS facilities were respectively $34.3 \pm 13.4$ and $32.2 \pm 12.4$. More males were treated for TB at the public DOTS facilities (M:F ratio $=1: 076)$ while at the private DOTS facilities the M:F ratio was almost equal (M:F $=1: 0.98)$. Over $60 \%$ of the TB cases reviewed were sputum smear positive. However, a significantly higher proportion of the sputum smear positive cases were managed at the private DOTS facilities $(\mathrm{p}<0.001)$. Of the patients that had HIV test done, $15.3 \%$ and $11.8 \%$ were HIV positive from the public and private DOTS facilities respectively as shown in Table 1.

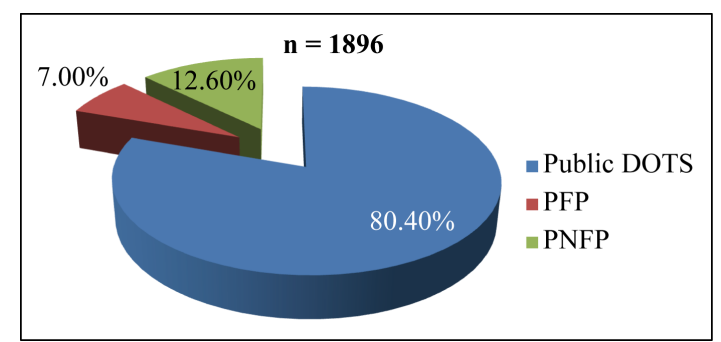

Figure 1. Proportion of treatment cards reviewed in different DOTS facilities.

Table 1. Socio demographic characteristics of TB patients at the public and private DOTS facilities.

\begin{tabular}{|c|c|c|c|c|}
\hline Variable & $\begin{array}{l}\text { Public DOTS } \\
\mathrm{n}=1524(\%)\end{array}$ & $\begin{array}{c}\text { Private DOTS } \\
\mathrm{n}=372(\%)\end{array}$ & $\chi^{2}$ & $\mathrm{p}$ \\
\hline \multicolumn{5}{|l|}{ Age group } \\
\hline Less than 15 & $36(2.4)$ & $8(2.2)$ & \multirow{6}{*}{6.723} & \multirow{6}{*}{0.151} \\
\hline $15-24$ & 322 (21.1) & 96 (25.8) & & \\
\hline $25-34$ & $528(34.6)$ & 136 (36.6) & & \\
\hline $35-44$ & 328 (21.5) & $72(19.4)$ & & \\
\hline 45 and above & 310 (20.3) & $60(16.1)$ & & \\
\hline Mean \pm SD & $34.3 \pm 13.4$ & $32.2 \pm 12.4$ & & \\
\hline \multicolumn{5}{|l|}{ Gender } \\
\hline Male & $860(56.4)$ & 188 (50.5) & \multirow{2}{*}{4.200} & \multirow{2}{*}{0.040} \\
\hline Female & 654 (43.6) & 184 (49.5) & & \\
\hline \multicolumn{5}{|l|}{ Pulmonary TB } \\
\hline Smear positive & 938 (61.5) & $280(75.3)$ & \multirow{2}{*}{24.503} & \multirow{2}{*}{$<0.001$} \\
\hline Smear negative & 586 (38.5) & $92(24.7)$ & & \\
\hline \multicolumn{5}{|l|}{ HIV status } \\
\hline Negative & 1154 (75.7) & $254(68.3)$ & \multirow{3}{*}{2.28} & \multirow{3}{*}{0.131} \\
\hline Positive & 208 (13.6) & $34(9.1)$ & & \\
\hline Not done $e^{\#}$ & 162 (10.6) & $84(22.6)$ & & \\
\hline
\end{tabular}

NB: ${ }^{\#}=$ Not included in the analysis. All participants in this study were Negros. 
Table 2 shows the management pattern of patients treated at the public and private DOTS facilities. HIV test was not done for a significantly higher proportion of patients managed (22.6\% vs $10.6 \%)$ at the private DOTS facilities $(\mathrm{p}<0.001)$. A slightly higher proportion of TB patients treated at the public DOTS facilities ( $2 \%$ vs $0.5 \%$ ) did not do smear microscopy before commencement of treatment and also did not do three follow up

Table 2. Management practices of at the public and private DOTS facilities.

\begin{tabular}{|c|c|c|c|c|}
\hline Variable & $\begin{array}{l}\text { Public DOTS } \\
\mathrm{n}=1524(\%)\end{array}$ & $\begin{array}{c}\text { Private DOTS } \\
\mathrm{n}=372(\%)\end{array}$ & $\chi^{2}$ & $\mathrm{p}$ \\
\hline \multicolumn{5}{|c|}{ Smear microscopy done before treatment } \\
\hline Yes & $1494(98.0)$ & 370 (99.5) & 3.690 & 0.055 \\
\hline No & $30(2.0)$ & $2(0.5)$ & & \\
\hline \multicolumn{5}{|l|}{ Had three follow up sputum } \\
\hline Yes & $698(45.8)$ & $177(47.6)$ & 0.381 & 0.537 \\
\hline No & $826(54.2)$ & $195(52.4)$ & & \\
\hline \multicolumn{5}{|c|}{ Number of follow up sputum done } \\
\hline None & $104(6.8)$ & $34(9.1)$ & 2.38 & 0.123 \\
\hline Once & $401(26.3)$ & $70(18.8)$ & 9.00 & 0.003 \\
\hline Twice & $321(21.1)$ & $90(24.2)$ & 1.73 & 0.189 \\
\hline Thrice & $698(45.8)$ & $178(47.8)$ & 0.51 & 0.477 \\
\hline \multicolumn{5}{|c|}{ Second month smear microscopy } \\
\hline Done & $1410(92.5)$ & $334(89.8)$ & 3.03 & 0.082 \\
\hline Not done & $114(7.5)$ & $38(10.2)$ & & \\
\hline \multicolumn{5}{|c|}{ Fifth month smear microscopy } \\
\hline Done & $921(60.4)$ & $251(67.5)$ & 6.28 & 0.012 \\
\hline Not done & $603(39.6)$ & $121(32.5)$ & & \\
\hline \multicolumn{5}{|c|}{ Seventh month smear microscopy } \\
\hline Done & $805(52.8)$ & 193 (51.9) & 0.11 & 0.745 \\
\hline Not done & $719(47.2)$ & $179(48.1)$ & & \\
\hline \multicolumn{5}{|c|}{ Weight measurement during treatment } \\
\hline None & $6(0.4)$ & $0(0.0)$ & 1.47 & $0.604^{x}$ \\
\hline Once & 318 (20.9) & $122(32.8)$ & 23.88 & $<0.001$ \\
\hline Twice & $390(25.6)$ & $96(25.8)$ & 0.01 & 0.932 \\
\hline At least thrice & $810(53.1)$ & $154(41.4)$ & 16.52 & $<0.001$ \\
\hline \multicolumn{5}{|l|}{ HIV test conducted } \\
\hline Yes & $1362(89.4)$ & $288(77.4)$ & 31.82 & $<0.001$ \\
\hline No & $162(10.6)$ & $84(22.6)$ & & \\
\hline \multicolumn{5}{|l|}{ Treatment category } \\
\hline Specified & $1514(99.3)$ & $372(100.0)$ & 2.454 & 0.117 \\
\hline Not specified & $10(0.7)$ & $0(0.0)$ & & \\
\hline \multicolumn{5}{|c|}{ Drug dosage according to patient's weight } \\
\hline Correctly done & $1380(90.6)$ & $264(71.0)$ & 99.50 & $<0.001$ \\
\hline Wrongly done & $144(9.4)$ & $108(29.0)$ & & \\
\hline \multicolumn{5}{|l|}{ Monitoring of treatment } \\
\hline No drug interruption & $1176(77.2)$ & $280(75.3)$ & 0.603 & 0.437 \\
\hline Drug interruption & $348(22.8)$ & $92(24.7)$ & & \\
\hline
\end{tabular}

Note: $\mathrm{X}=$ Fisher's exact test. 
sputum $(54.2 \%$ vs 52.4\%) $(\mathrm{p}<0.05)$ during the entire treatment duration. However, more of the patients treated at the public DOTS facilities did weight measurements (53.1\% vs $41.4 \%$ ) and had the correct dosage of TB drugs based on weight $(90.6 \%$ vs $71.0 \%)$ compared with those managed at the private DOTS facilities ( $<<$ 0.001). A higher proportion of patients managed at the private DOTS facilities interrupted treatment $(22.8 \%$ vs 24.7\%) compared with those managed at the public DOTS facilities $(\mathrm{p}=0.437)$.

Recording of sputum smear results ( $7.7 \%$ vs $14.0 \%)$, treatment outcome (43.8\% vs $53.8 \%)$ and filling of the treatment cards (22.6\% vs $32.8 \%$ ) were poorly done for significantly higher proportion of patients managed at the private DOTS facilities compared with those treated at the public DOTS facilities as shown in Table 3. Table 4 shows the proportion of patients treated in full adherence with the national guidelines at the public and private DOTS facilities. Overall, the proportion of patients treated full adherence with the national guidelines was low in both the public and private DOTS facilities. About 19\%, 25\% and none of the cases seen at the public PNFP and PFP DOTS facilities were treated in full adherence with the NTBLCP guidelines respectively ( $\mathrm{p}<$ 0.001). Table 5 shows that a significantly higher proportion of adults, smear positives and those that had successful treatment were treated in full compliance with the national guidelines $(\mathrm{p}<0.05)$.

\section{Discussion}

One of the goals of the public private mix (PPM) for TB is to provide rational and standardized treatment to TB patients especially those managed at the private sector, thereby reducing the spread of TB within the community and emergence of multi drug resistance TB. Routinely, the NTBLCP and the LSTBLCP organizes training and retraining programs for health care workers at the public DOTS facilities and private sector involved in the PPM. This training is expected to facilitate adherence with the national guidelines. This study however shows that the proportion of patients managed in full adherence with the national guidelines at the public and private DOTS facilities was low. Particularly striking was the fact that none of the patients managed at the PFP facilities were managed in full adherence with the national guidelines. Studies from Nigeria and other high TB burden countries have shown that private practitioners and health care workers from the public sector do not comply with the National Tuberculosis Programme (NTP) [7]-[10].

Many reasons have been shown to be responsible for the poor adherence of health care workers at the TB treatment centers. Some studies found that insufficient knowledge of health workers at the public and private

\begin{tabular}{|c|c|c|c|c|}
\hline Variable & $\begin{array}{l}\text { Public DOTS } \\
\mathrm{n}=1524(\%)\end{array}$ & $\begin{array}{c}\text { Private DOTS } \\
\mathrm{n}=372(\%)\end{array}$ & $\chi^{2}$ & $\mathrm{p}$ \\
\hline \multicolumn{5}{|c|}{ Recording of smear results } \\
\hline Correctly recorded & $1406(92.3)$ & $320(86.0)$ & \multirow{2}{*}{14.25} & \multirow{2}{*}{$<0.001$} \\
\hline Wrongly recorded & $118(7.7)$ & $52(14.0)$ & & \\
\hline \multicolumn{5}{|l|}{ Treatment outcome } \\
\hline Documented & $856(56.2)$ & $172(46.2)$ & \multirow{2}{*}{11.88} & \multirow{2}{*}{0.001} \\
\hline Not documented & $668(43.8)$ & $200(53.8)$ & & \\
\hline \multicolumn{5}{|l|}{ Treatment card } \\
\hline Correctly filled & $1180(77.4)$ & $250(67.2)$ & \multirow{2}{*}{18.88} & \multirow{2}{*}{$<0.001$} \\
\hline Not correctly filled & $344(22.6)$ & $122(32.8)$ & & \\
\hline
\end{tabular}

Table 4. Compliance to national guidelines in the different types DOTS facilities.

\begin{tabular}{|c|c|c|c|c|}
\hline \multirow[b]{2}{*}{ Type of health facility } & \multicolumn{2}{|c|}{ Compliance } & \multirow[b]{2}{*}{$\chi^{2}$} & \multirow[b]{2}{*}{$\mathrm{p}$} \\
\hline & $\begin{array}{c}\text { Partial } \\
\mathrm{n}=1544(\%)\end{array}$ & $\begin{array}{c}\text { Full } \\
\mathrm{n}=352(\%)\end{array}$ & & \\
\hline Public & $1232(80.8)$ & $292(19.2)$ & 37.02 & $<0.001$ \\
\hline Private for profit & $132(100.0)$ & $0(0.0)$ & & \\
\hline Private not for profit & $180(75.0)$ & $60(25.0)$ & & \\
\hline
\end{tabular}


Table 5. Factors associated with compliance of healthcare workers to the NTP guidelines.

\begin{tabular}{|c|c|c|c|c|}
\hline \multirow[b]{2}{*}{ Variables } & \multicolumn{2}{|c|}{ Compliance with NTP } & \multirow[b]{2}{*}{$\chi^{2}$} & \multirow[b]{2}{*}{$\mathrm{p}$} \\
\hline & $\begin{array}{c}\text { Partial } \\
\text { freq (\%) }\end{array}$ & $\begin{array}{c}\text { Full } \\
\text { freq (\%) }\end{array}$ & & \\
\hline \multicolumn{5}{|l|}{ Age group } \\
\hline Children & $42(95.5)$ & $2(4.5)$ & \multirow{2}{*}{5.856} & \multirow{2}{*}{$0.010^{x}$} \\
\hline Adults & $1502(81.1)$ & 350 (18.9) & & \\
\hline \multicolumn{5}{|l|}{ Gender } \\
\hline Male & 868 (82.8) & $180(17.2)$ & \multirow{2}{*}{2.994} & \multirow{2}{*}{0.084} \\
\hline Female & 676 (79.7) & $172(20.3)$ & & \\
\hline \multicolumn{5}{|l|}{ Type of TB } \\
\hline Smear Positive & $866(71.1)$ & 352 (28.9) & \multirow{2}{*}{240.61} & \multirow{2}{*}{$<0.001^{x}$} \\
\hline Smear Negative & $678(100.0)$ & $0(0.0)$ & & \\
\hline \multicolumn{5}{|l|}{ Treatment outcome } \\
\hline Treatment success & $1218(77.6)$ & $352(22.4)$ & \multirow{2}{*}{89.75} & \multirow{2}{*}{$<0.001^{\rtimes}$} \\
\hline No treatment success & $326(100.0)$ & $0(0.0)$ & & \\
\hline HIV status & $\mathrm{n}=1298(\%)$ & $\mathrm{n}=352(\%)$ & & \\
\hline Positive & $196(81.0)$ & $46(19.0)$ & \multirow{2}{*}{0.91} & \multirow{2}{*}{0.339} \\
\hline Negative & $1102(78.3)$ & 306 (21.7) & & \\
\hline
\end{tabular}

sector about the guidelines was responsible for the poor adherence [8] [11]. Other studies also showed that some health workers refused to comply despite their awareness of the NTP guidelines although reasons for their refusal were not highlighted [12] [13].

Health care workers are usually trained before they were allowed to provide TB services. However, maintaining trained staff has been a major challenge in the TB programme especially in a cosmopolitan city like Lagos. The high staff turnover experienced in the private sector maybe due to poor job satisfaction and/or job insecurity. In addition, the regular redeployment and poor distribution of trained staff within the public health sector is a cause of concern in the sustainability of public health programmes in developing countries like Nigeria [14]-[16].

Sputum microscopy is the main diagnostic tool for pulmonary tuberculosis and all presumptive TB clients should have sputum microscopy as the first diagnostic tool. In this study almost all the patients managed at the public and private DOTS facilities did sputum smear microscopy before commencement of anti-TB treatment. This is similar to findings from studies from Nigeria and elsewhere [9] [11] [17] [18]. However other studies from another part of Nigeria and Ethiopia showed that some of the patients treated at the public and private DOTS facilities did not do smear microscopy before initiation of anti-TB treatment [7] [19]. Less than half of the patients managed at the public and private DOTS facilities had three follow up sputum smear microscopy in this study. This may be due to shortages of laboratory equipment and supplies in some of the DOTS laboratories in Lagos [20] which has also been reported in other studies from Ghana, India and Ethiopia [19] [21] [22] and the incessant strike action by health care workers in Lagos Nigeria also contributed to failure of patients to do follow up sputum microscopy.

There is a strong synergy between TB and HIV/AIDS and the WHO recommends HIV testing for TB patients to reduce the burden of TB/HIV [23]. In this study, a high proportion of patients managed at the public and private DOTS facilities did HIV test which was consistent with findings from another study from another part of the country [6] but higher than what was reported in a similar study from Ethiopia [19]. Majority of the Anti retrovital therapy (ART) centres in Lagos state are located at the public health care facilities. This may explain why a significantly higher proportion of patients managed at the public DOTS facilities did HIV test compared with those managed at the private DOTS facilities.

One of the goals of the NTBLCP was to increase the success rate of TB patients [1]. In order to achieve this target, TB patients must be treated in full adherence with the NTP guidelines. This study shows that none of the 
patients that had unsuccessful treatment at the public and private DOTS facilities were treated in full adherence with the NTP guidelines. A WHO report documented that within 10 years of DOTS implementation, 16 million people globally were cured [24] in addition to the reduction in incidence of TB in most region of the world except the sub Saharan Africa. For the NTBLCP to achieve the global targets, it is paramount that patients are treated according to the NTP guidelines irrespective of their age, gender, sputum smear results and HIV status.

\section{Limitation}

The study was a retrospective review of treatment cards and as such did not consider other factors such as training of health personnel at DOTs facilities, availability laboratory equipment and supplies and provision of logistic necessary to track patients lost to follow which could affect adherence to the national guidelines.

\section{Conclusion}

Majority of the patients treated at the public and private DOTS facilities in Lagos State were not treated in full adherence with the national guidelines. There is an urgent need for the LSTBLCP to reorient health care providers in public and private health facilities to ensure full adherence with the national guidelines on the management of TB in Nigeria.

\section{Acknowledgements}

The authors wish to acknowledge all the Lagos State TB control officer, TB focal persons, LGA TB supervisors and the Lagos State Ministry of Health for their support. The research was self funded; the findings and conclusion are those of the authors.

\section{Competing Interests}

Authors have declared that no competing interests exist.

\section{Authors Contribution}

OAA conceived the study, involved with data collection, data analysis and discusssion. OJD wrote the methodology and was involved in the writing process, MD was involved in reading the manuscript and literature search, ENA was involved in data collection and proff reading the manuscript. EOJ and OEI were involved with data collection and literature search while OOO supervised the research.

\section{References}

[1] Federal Ministry of Health. National Tuberculosis and Leprosy Control Programmes (2014) Nigeria 2013 NTBLCP Annual Report.

http://stoptbng.org/wp-content/uploads/2014/08/2013-ANNUAL-REPORT-NATIONAL-TUBERCULOSIS-LEPROS Y-CONTROL-PROGRAMME.pdf

[2] World Health Organization (2014) First National TB Prevalence Survey 2012 Nigeria. http://www.who.int/tb/publications/NigeriaReport WEB NEW.pdf

[3] World Health Organization (2013) Global Tuberculosis Report 2013. http://www.who.int/tb/publications/global_report/en/

[4] World Health Organization (2006) Global Tuberculosis Control, Surveillance, Planning and Financing, STOP TB Department, WHO Report 2006. http://whqlibdoc.who.int/hq/2006/TDR_SWG_06_eng.pdf

[5] Ibrahim, L.M., Hadjia, I.S., Nguku, P., Waziri, N.E., Akhimien, M.O., Patrobas, P. and Nsubuga, P. (2014) Health Care Workers' Knowledge and Attitude towards TB Patients under Direct Observation of Treatment in Plateau State Nigeria. Pan African Medical Journal, 18, 1-8. http://dx.doi.org/10.11604/pamj.supp.2014.18.1.3408

[6] Federal Ministry of Health (2012) National Tuberculosis and Leprosy Control Programme. Models for Training of General Health Care Workers on Tuberculosis Control. 4th Edition, Sounasprints, Abuja.

[7] Oshi, D.C., Chukwu, J.N., Nwafor, C.C., Aguwa, E.N., Onyeonoro, U.U., Meka, A., Ikebudu, J.N., Anyim, M.C., Ekeke, N., Omotowo, B., Ogbudebe, C. and Madichie, N.O. (2014) Diagnosis of Smear-Negative Tuberculosis in Nigeria: Do Health Care Workers Adhere to the National Guidelines? International Journal of Mycobacteriology, 3, 163167. http://dx.doi.org/10.1016/j.ijmyco.2014.07.005 
[8] Zheng, X., Zhong, F. and Zhang, X. (2014) Doctors' Compliance with National Guidelines and Clinical Pathway on the Treatment of Tuberculosis in Patients in Hubei, China. Journal of Evaluation in Clinical Practice, 20, 288-293. http://dx.doi.org/10.1111/jep.12127

[9] Bharaswadkar, S., Kanchar, A., Thakur, N., Shah, S., Patnaik, B., et al. (2014) Tuberculosis Management Practices of Private Practitioners in Pune Municipal Corporation, India. PLoS ONE, 9, e97993. http://dx.doi.org/10.1371/journal.pone.0097993

[10] Greaves, F., Ouyang, H., Pefole, M., MacCarthy, S. and Cash, R.A. (2007) Compliance with DOTS Diagnosis and Treatment Recommendations by Private Practitioners in Kerala, India. International Journal of Tuberculosis and Lung Disease, 11, 110-112.

[11] Okeke, T.A. and Aguwa, E.N. (2006) Evaluation of the Implementation of Directly Observed Treatment Short Course by Private Medical Practitioners in the Management of Tuberculosis in Enugu, Nigeria. Tanzania Health Research Bulletin, 8, 86-89.

[12] Shah, S.K., Sadiq, H., Khalil, M., Noor, A., Rasheed, G., Shah, S.M. and Ahmad, N. (2003) Do Private Doctors Follow National Guidelines for Managing Pulmonary Tuberculosis in Pakistan. Eastern Mediterranean Health Journal, 9, 776-788.

[13] Yadav, A., Garg, S.K., Chopra, H., Bajpai, S.K., Bano, T., Jain, S. and Kumar, A. (2012) Treatment Practices in Pulmonary Tuberculosis by Private Sector Physicians of Meerut, Uttar Pradesh. The Indian Journal of Chest Diseases \& Allied Sciences, 54, 161-164.

[14] Adejumo, A.O., Daniel, O.J., Kuyinu, Y.A., Wright, K.O., Jaiyesimi, E.O. and Odusanya, O.O. (2015) Awareness and Knowledge of Health Care Workers at Dots Facilities on the Management of Tuberculosis in Lagos, Nigeria: A PublicPrivate Comparison. British Journal of Applied Science \& Technology, 12, 1-8. http://dx.doi.org/10.9734/BJAST/2016/21206

[15] Figueroa-Munoz, J., Palmer, K., Dal Poz, M.R., Blanc, L., Bergstrom, K. and Raviglione, M. (2005) The Health Workforce Crisis in TB Control: A Report from High-Burden Countries. Human Resources for Health, 3, 1-9. http://dx.doi.org/10.1186/1478-4491-3-2

[16] Mesfin, M.M., Newell, J.N., Walley J.D., Gessessew, A., Tesfaye, T., Lemma, F. and Madeley, R.J. (2009) Quality of Tuberculosis Care and Its Association with Patient Adherence to Treatment in Eight Ethiopian Districts. Health Policy and Planning, 24, 457-466. http://dx.doi.org/10.1093/heapol/czp030

[17] Geremew, T., Jira, C. and Girma, F. (2011) Assessment of Quality of Care Delivered for Infectious Pulmonary Tuberculosis Patients in Jimma Zone, South West Ethiopia. Ethiopian Journal of Health Sciences, 21, 39-48.

[18] Krishnan, N., Ananthakrishnan, R., Augustine, S., Vijayalaxmi, N., Gopi, P., Kumaraswami, V. and Narayanan, P.R. (2009) Impact of Advocacy on Tuberculosis Management Practices of Private Practitioners in Chennai City, India. International Journal of Tuberculosis and Lung Disease, 13, 112-118.

[19] Gebrekidan, G., Tesfaye, G., Hambisa, M.T. and Deyessa, N. (2014) Quality of Tuberculosis Care in Private Health Facilities of Addis Ababa, Ethiopia. Tuberculosis Research and Treatment, 2014, Article ID: 720432. http://dx.doi.org/10.1155/2014/720432

[20] Adejumo, O.A., Femi-Adebayo, T., Daniel, O.J., Adejumo, E.N., Abdur-Razzaq, H. and Odusanya, O.O. (2015) A Comparative Assessment of Public and Private DOTS Laboratories in the Lagos State TB Control Programme. African Journal of Clinical and Experimental Microbiology, 16, 79-85. http://dx.doi.org/10.4314/ajcem.v16i2.6

[21] Addo, K.K., Owusu-Darko, K., Dan-Dzide, M., Yeboah-Manu, D., Ablordey, A., Caulley, P., et al. (2006) Situation Analysis of TB Microscopy Centres in Ghana. International Journal of Tuberculosis and Lung Disease, 10, 870-875.

[22] Joncevska, M. (2004) Laboratory Assessment Report Tajikistan. Project HOPE. http://pdf.usaid.gov/pdf_docs/PNADP438.pdf

[23] World Health Organization (2012) WHO Policy on Collaborative TB/HIV Activities: Guidelines for National Programs and Other Stakeholders. http://www.who.int/iris/bitstream/10665/44789/1/9789241503006 eng.pdf

[24] World Health Organization (2006) WHO-Stop TB Partnership. The Stop TB Strategy: Building and Enhancing DOTS to Meet the TB Related Millennium Developmental Goals.

http://www.who.int/tb/publications/2006/stop_tb_strategy.pdf 